\title{
A new sonochemical method for preparation of different morphologies of $\mathrm{CuInS}_{2}$ nanostructures
}

\author{
OMID AMIRI ${ }^{\mathrm{a}}$, MASOUD SALAVATI-NIASARI ${ }^{\mathrm{b}, *}$, MEHDI MOUSAVI-KAMAZANI ${ }^{\mathrm{a}}$, \\ DAVOOD GHANBARI ${ }^{\mathrm{c}}$ MOHAMMAD SABET $^{\mathrm{b}}$ and KAMAL SABERYAN ${ }^{\mathrm{d}}$ \\ ${ }^{a}$ Young Researchers Club, Kashan Branch, Islamic Azad University, Kashan, Iran \\ bInstitute of Nano Science and Nano Technology, University of Kashan, P.O. Box 87317-51167, Kashan, Iran \\ ${ }^{\mathrm{c}}$ Young Researchers Club, Arak Branch, Islamic Azad University, Arak, Iran \\ ${ }^{\mathrm{d}}$ Fuel Cycle Research School, NSTRI, P.O. Box 11365-8486, Tehran, Iran
}

MS received 16 January 2013; revised 10 March 2013

\begin{abstract}
CuInS}_{2}$ nanostructures were synthesized by sonochemical route using (bis(salicylate)copper(II)) as a new copper precursor. The effects of different parameters such as sulphur source, solvent, power of irradiation and reaction time on the morphology of the products were investigated. Nanostructures were characterized by X-ray diffraction (XRD), scanning electron microscopy (SEM), transmission electron microscopy (TEM), photoluminescence (PL) and Fourier transform infrared (FT-IR) spectroscopy. CuInS ${ }_{2}$ nanostructures paste was prepared by doctor's blade technique on the transparent conductive oxide (TCO). The fill factor $(\mathrm{FF})$, open circuit voltage $\left(V_{\mathrm{oc}}\right)$, and short circuit current $\left(I_{\mathrm{sc}}\right)$ were obtained by $I-V$ characterization.
\end{abstract}

Keywords. CuInS 2 ; solar cells; ultrasonic; semiconductors.

\section{Introduction}

I-III-IV 2 ternary chalcopyrite semiconductors have great potential for photovoltaic, non-linear optic and other optoelectronic applications (Shay et al 1975; Yamamoto et al 1997). CuInS 2 with chalcopyrite structures has attracted considerable attention as a suitable material for fabricating low-cost and efficient solar cells. CuInS (CIS) with its band gap ( $1.53 \mathrm{eV})$ at room temperature is an ideal solar absorber material (Moller et al 1998; Nekamp et al 2000; Kaiser et al 2001; Emst et al 2003; Klaer et al 2007). Therefore, many investigations have been employed for this substance and various $\mathrm{CuInS}_{2}$ nanostructures such as nanoparticles (Castro et al 2003; Dutta et al 2006), hollow nanospheres (Zhang et al 2003) and nanorods (Jiang et al 2000, Xiao et al 2001) were prepared. Different chemical methods, such as solvothermal reactions (Du et al 2007; Long et al 2010), and microwave irradiation (Gardner et al 2008) have been used to prepare this material. Jiang et al (2008) synthesized colloidal $\mathrm{CuInS}_{2}$ nanocrystals from a single-source molecular precursor $\left(\mathrm{PPh}_{3}\right)_{2} \mathrm{CuIn}(\mathrm{SEt})_{4}$. Nairn et al (2006) synthesized $\mathrm{CuInS}_{2}$ nanoparticles by decomposing a molecular precursor using ultra-violet irradiation.

Sonochemical method is a facile route operated under ambient conditions. Ultrasonic irradiation caused cavitation

\footnotetext{
*Author for correspondence (salavati@kashanu.ac.ir)
}

in a liquid medium, where formation, growth and implosive collapse of bubbles occurred. The collapse of bubbles with short lifetimes produces intense local heating and high pressure. These localized hot spots can generate temperature of about $5000{ }^{\circ} \mathrm{C}$ and pressure of over $1800 \mathrm{kPa}$ that these spots are appropriate for many chemical reactions (Salavati-Niasari et al 2011; EsmaeiliZare et al 2012). In this work, $\mathrm{CuInS}_{2}$ nanostructures were synthesized by a simple sonochemical method using a new inorganic precursor. Salicylate as ligand with high steric hindrance is a suitable capping agent for preparation of nanostructures. The effect of various sulphur sources on the morphology of the product has also been investigated.

\section{Experimental}

\subsection{Physical measurements and materials}

All the chemical reagents were used as received without further purification. A multiwave ultrasonic generator (Sonicator 3000; Bandeline, MS 72, Germany), equipped with a converter/transducer and titanium oscillator (horn), $12.5 \mathrm{~mm}$ in diameter, operating at $20 \mathrm{kHz}$ with a maximum power output of $100 \mathrm{~W}$, was used for the ultrasonic irradiation. The ultrasonic generator automatically adjusted the power level. The wave amplitude in each experiment was adjusted as needed. XRD patterns were recorded by a Philips, X-ray diffractometer using Ni-filtered CuK $\alpha$ radiation. Scanning electron microscopy (SEM) images 
were obtained from LEO instrument model 1455VP. Prior to taking images, all samples were coated with a very thin layer of Pt to make the sample surface conductive and to prevent charge accumulation. Fourier transform infrared (FT-IR) spectra were recorded on Shimadzu Varian 4300 spectrophotometer in $\mathrm{KBr}$ pellets. Room temperature photoluminescence (PL) was studied by an F-4500 fluorescence spectrophotometer. Transmission electron microscopy images were obtained on a Philips EM208 microscope with an accelerating voltage of $100 \mathrm{kV}$.

\subsection{Preparation of $\mathrm{CuInS}_{2}$ nanostructures}

The copper salicylate $\left[\mathrm{Cu}(\mathrm{Hsal})_{2}\right]$ precursor was prepared from the reaction of $1 \mathrm{mmoL}$ of copper sulphate penta hydrate and $2 \mathrm{mmoL}$ of sodium salicylate. $\mathrm{CuInS}_{2}$ nanoparticles were prepared by the reaction of $\mathrm{Cu}(\mathrm{Hsal})_{2}$ and $\mathrm{InCl}_{3}$ with a sulphur source in propylene glycol (PG) as solvent. $50 \mathrm{mg}$ of $\mathrm{Cu}(\mathrm{Hsal})_{2}, 20 \mathrm{mg}$ of $\mathrm{InCl}_{3}$ and $5 \mathrm{mg}$ of SDS were dissolved in $60 \mathrm{~mL}$ of PG and was irradiated under ultrasound waves. Different sulphur sources (2 mmoL) such as sodium sulphite $\left(\mathrm{Na}_{2} \mathrm{~S}_{2} \mathrm{O}_{3}\right)$, thiourea (TU), thioacetamide (TAA), thiosemicarbazide (TSC), L-cysteine (L-Cyst) and carbon disulfide $\left(\mathrm{CS}_{2}\right)$ were added dropwise to the solution. The black precipitate was washed with ethanol and deionized water. The product was dried at $60{ }^{\circ} \mathrm{C}$ for $3 \mathrm{~h}$ under vacuum. The precipitates were annealed under argon atmosphere at $450{ }^{\circ} \mathrm{C}$ for $2 \mathrm{~h}$. The annealing converted the mixture of $\mathrm{In}_{2} \mathrm{~S}_{3}$ and $\mathrm{CuS}$ into $\mathrm{CuInS}_{2}$. More details of experiment are given in table 1.

\subsection{Preparation of CuInS $\mathrm{I}_{2}$ electrodes}

The transparent conductive oxide (TCO) glass used as current collector (solar $4 \mathrm{~mm}$ thickness, pilkington, tec 7 , Japan). CIS electrode was prepared by Dr-blading of $\mathrm{CuInS}_{2}$ paste on TCO. The electrode configuration was a

Table 1. Experimental conditions for preparation of $\mathrm{CuInS}_{2}$.

\begin{tabular}{lclcc}
\hline $\begin{array}{l}\text { Sample } \\
\text { no. }\end{array}$ & Solvent & $\begin{array}{l}\text { Sulphur } \\
\text { source }\end{array}$ & $\begin{array}{c}\text { Time } \\
\text { (min) }\end{array}$ & $\begin{array}{c}\text { Power } \\
\text { (W) }\end{array}$ \\
\hline 1 & PG & $\mathrm{Na}_{2} \mathrm{~S}_{2} \mathrm{O}_{3}$ & 40 & 70 \\
2 & PG & Tu & 40 & 70 \\
3 & PG & TGA & 40 & 70 \\
4 & PG & TAA & 40 & 70 \\
5 & PG & TSC & 40 & 70 \\
6 & PG & L-Cyst & 40 & 70 \\
7 & PG & CS & 40 & 70 \\
8 & PG & L-Cyst & 30 & 70 \\
9 & PG & L-Cyst & 50 & 70 \\
10 & H2O & L-Cyst & 40 & 70 \\
11 & Gly & L-Cyst & 40 & 70 \\
12 & PG & L-Cyst & 40 & 50 \\
13 & PG & L-Cyst & 40 & 60 \\
\hline
\end{tabular}

transparent layer of nanocrystalline $\mathrm{CuInS}_{2}$ with an average size of $24 \mathrm{~nm}$ and a microcrystalline scattering layer. The as-prepared electrodes were sintered at $450{ }^{\circ} \mathrm{C}$ for 30 min. CdS QDs are deposited on the $\mathrm{CuInS}_{2}$ film by chemical bath deposition method (Zhu et al 2010). $\mathrm{CuInS}_{2}$ film was dipped into a solution containing $\mathrm{Cd}\left(\mathrm{NO}_{3}\right)_{2}\left(0.25 \mathrm{M}\right.$ in ethanol) and $\mathrm{CH}_{4} \mathrm{~N}_{2} \mathrm{~S}(0.25 \mathrm{M}$ in methanol), respectively. The procedure was repeated for several cycles and each cycle prolongs by $20 \mathrm{~s}$.
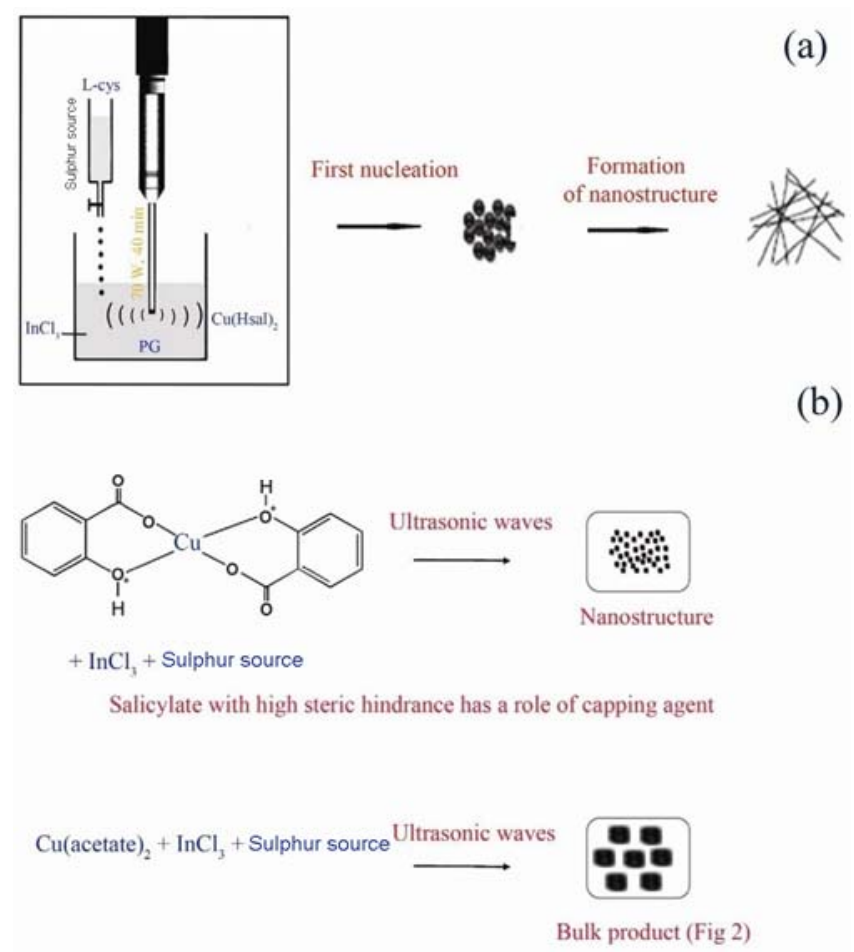

Figure 1. Schematic diagram of (a) formation of nanostructures and (b) effect of salicylate on the particle size.

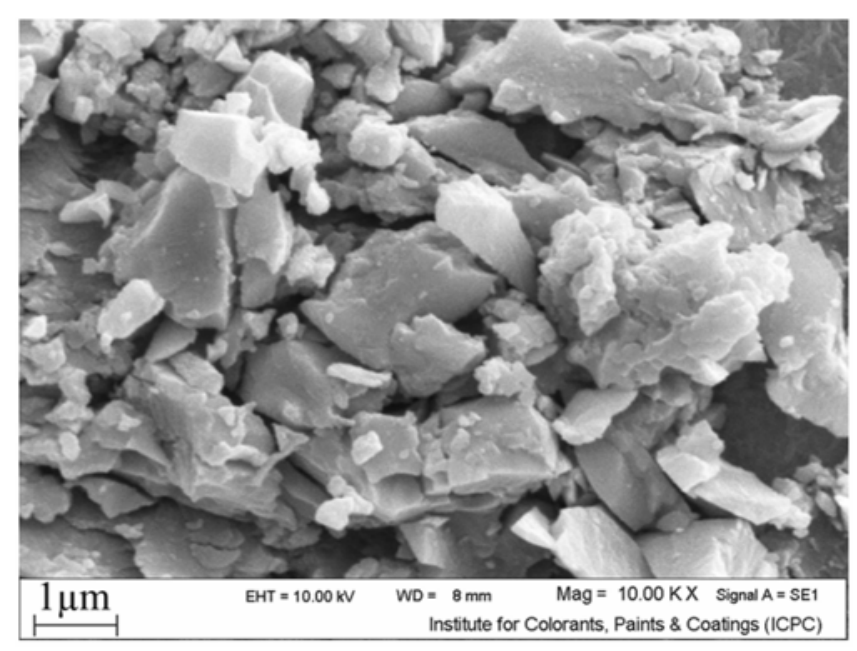

Figure 2. SEM image of the $\mathrm{CuInS}_{2}$ synthesized using copper acetate (without using salicylate). 


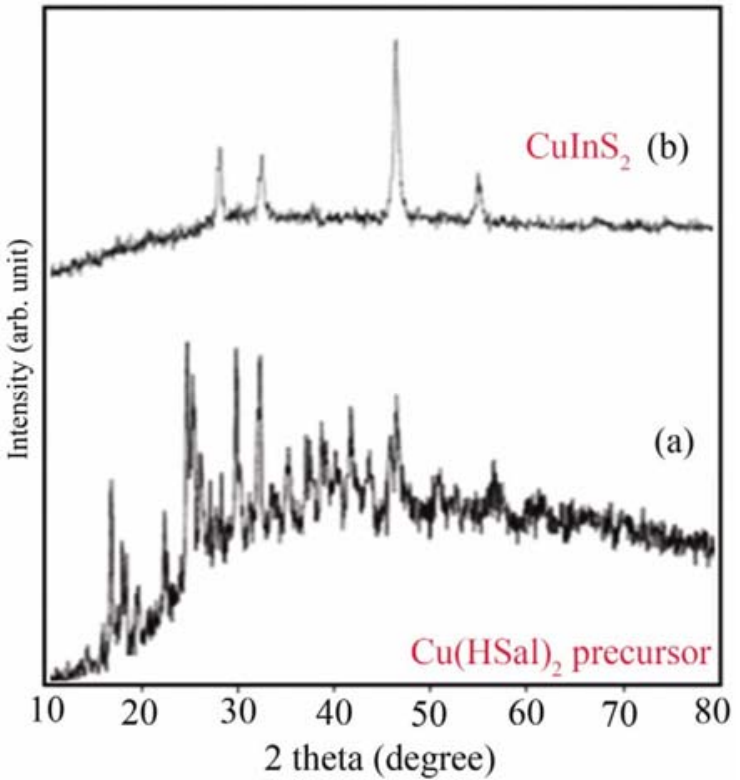

Figure 3. XRD pattern of (a) copper salicylate and (b) $\mathrm{CuInS}_{2}$ nanoparticles (sample no. 4).

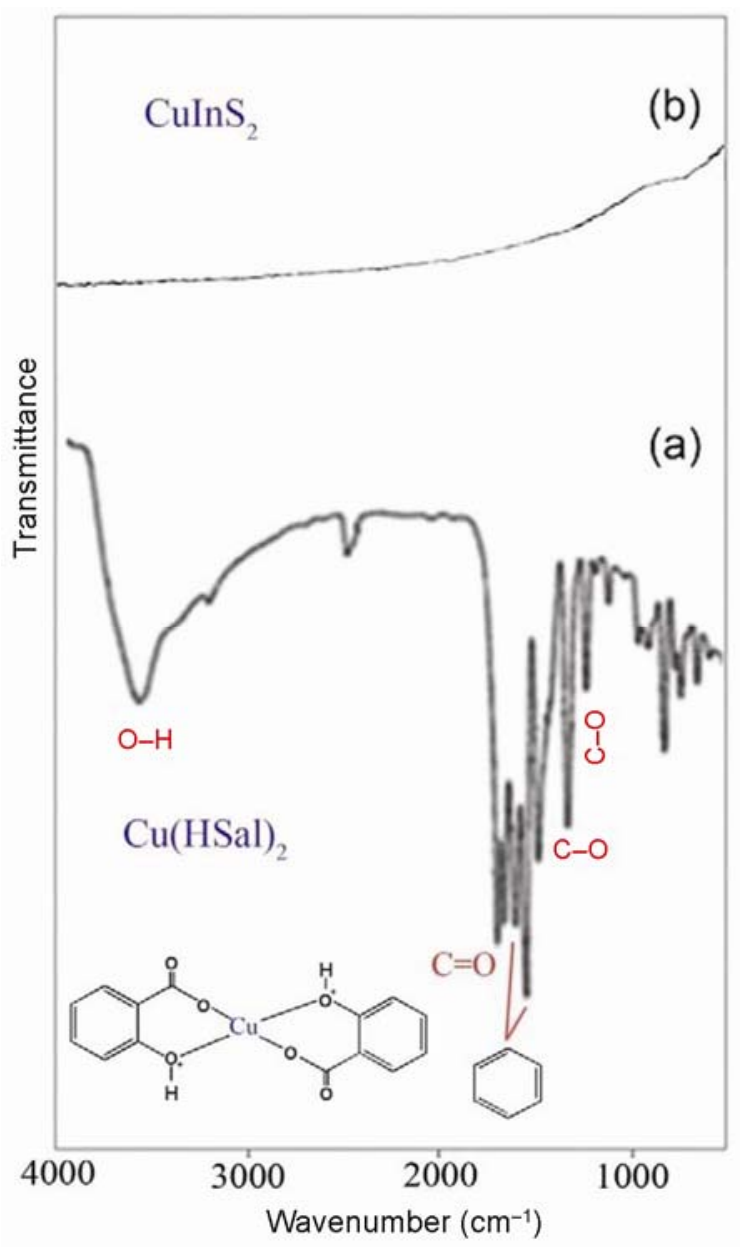

Figure 4. FT-IR spectrum of as-synthesized (a) $\mathrm{Cu}(\mathrm{Hsal})_{2}$ and (b) $\mathrm{CuInS}_{2}$ (sample no. 4).

\section{Results and discussion}

Schematic of nanostructures formation is depicted in figure 1(a). SEM image of synthesized product using pure copper acetate is shown in figure 2 results show that without using salicylate, bulk product is obtained. Salicylate with high steric hindrance is a suitable capping agent for preparation of nanostructures. Ligand group that exist in the surroundings of copper causes less availability of metal, so nucleation occurs over the growth (figure $1 \mathrm{~b}$ ).

Figure 3(a) shows XRD pattern of $\mathrm{Cu}(\mathrm{Hsal})_{2}$ precursor and figure 3(b) depicts pattern of the $\mathrm{CuInS}_{2}$ obtained after annealing at $450{ }^{\circ} \mathrm{C}$. The strong and sharp diffraction peaks confirm good crystallinity of the product. Pattern of the $\mathrm{CuInS}_{2}$ show a pure tetragonal structure with suitable agreement to literature value (JCPDS card no. 75-0106, Space group: 1-42d, lattice constants: $a=5.5170, b=5.5170$ and $c=11.0600)$. The crystallite size $\left(D_{\mathrm{c}}\right)$ of the as-prepared $\mathrm{CuInS}_{2}$ was calculated to be $26 \mathrm{~nm}$ using the Debeye-Scherrer equation:

$$
D_{\mathrm{c}}=\frac{K \lambda}{\beta \cos \theta},
$$

where $\beta$ is the breadth of the observed diffraction line at its half intensity maximum, $K$ the shape factor, which usually takes a value of about 0.9 and $\lambda(0.154 \mathrm{~nm})$ is the wavelength of the X-ray source used in XRD.

FT-IR spectrum of as-synthesized $\mathrm{Cu}(\mathrm{Hsal})_{2}$ is illustrated in figure 4(a). Absorption at $1602 \mathrm{~cm}^{-1}$ is related to $\mathrm{C}=\mathrm{O}$ bond and absorptions at 1245 and $1150 \mathrm{~cm}^{-1}$ are attributed to $\mathrm{C}-\mathrm{O}$ bonds. Peaks at 1457 and $1567 \mathrm{~cm}^{-1}$ are responsible for stretching vibrations of aromatic ring. Absorption at 3419 is related to O-H bonds. FT-IR spectrum of CuInS $\mathrm{S}_{2}$ nanostructures is depicted in figure 4(b), since pure $\mathrm{CuInS}_{2}$ has no absorption peaks in the range of $4000-400 \mathrm{~cm}^{-1}$; the result shows that the product did not have major IR-active impurity.

Synthesis of $\mathrm{CuInS}_{2}$ at $70 \mathrm{~W}$ for $40 \mathrm{~min}$ has been selected as a basic reaction in this work and the effect of different parameters on the morphology of the products has been investigated. SEM images of the CuInS 2 nanoparticles prepared by different sulphur source are illustrated in figures 5(a-f). SEM images of the products with thiosemicarbazide, thiourea and thioacetamide are depicted in figure 5(a-c), respectively. Ultrasonic irradiation creates bubbles that produce high temperature and energy after decomposition. This process provides appropriate amounts of energy for formation of nanoparticles. L-cysteine was used as a sulphur source and capping agent simultaneously for forming nanoflowers (figure 5d). Figures 5(e and f) show SEM images of synthesized products by thioglycolic acid and sodium sulphite. By using ultrasound irradiation, the formed bubbles collapse, resulting in the generation of high-speed microjets that can generate nanoparticles. 

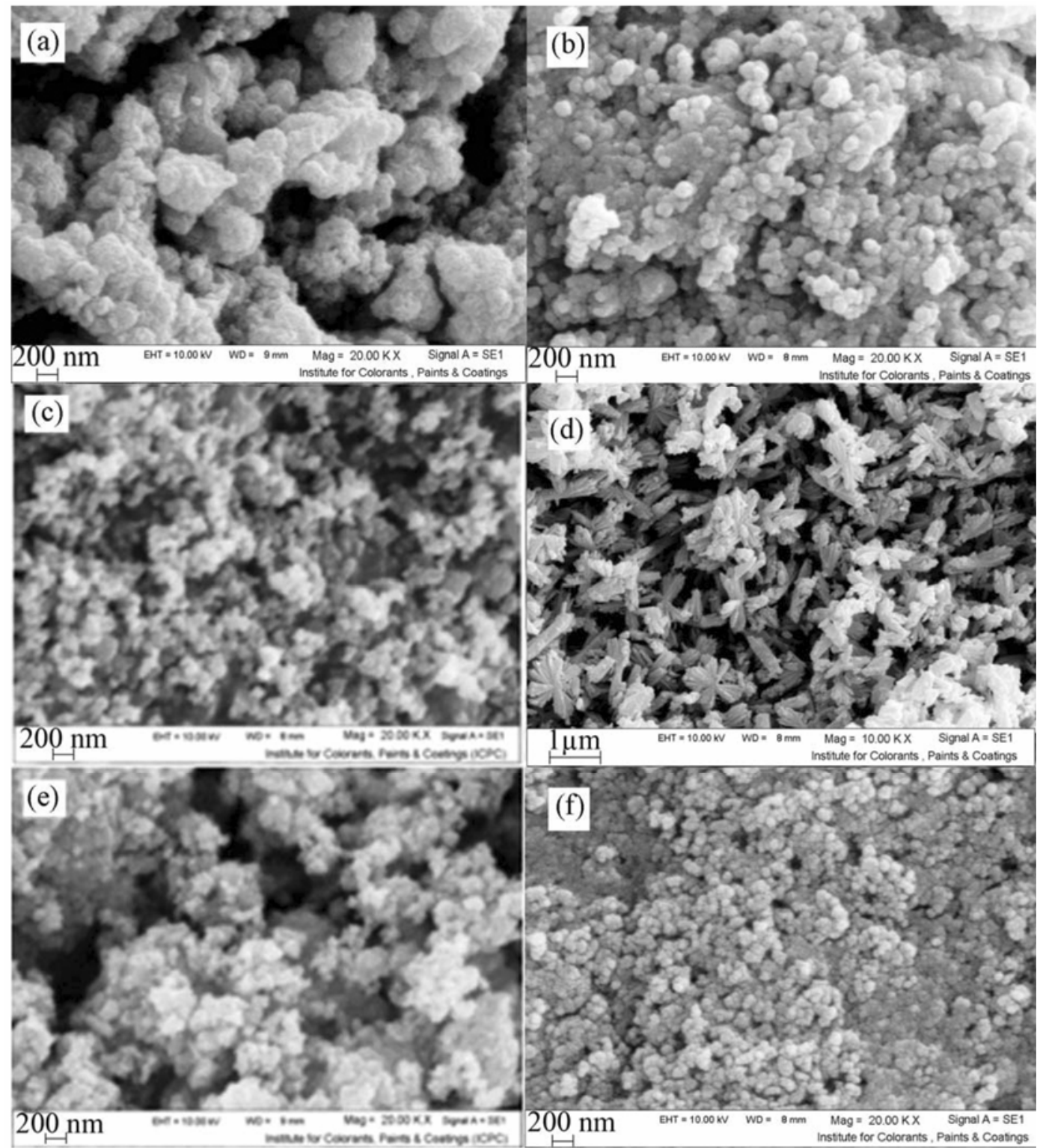

Figure 5. SEM images of the $\mathrm{CuInS}_{2}$ nanostructure with (a) TSC (sample no. 5), (b) Tu (sample no. 2), (c) TAA (sample no. 4), (d) L-cyst (sample no. 6), (e) TGA (sample no. 3) and (f) $\mathrm{Na}_{2} \mathrm{~S}_{2} \mathrm{O}_{3}$ (sample no. 1).

For investigating the effect of sonication time on the morphology of the products, the reaction was carried out in 30,40 and $50 \mathrm{~min}$. According to the figure 6(a), spherical nanoparticles were achieved; it seems that at $30 \mathrm{~min}$, nanoparticles do not have time to agglomerate. By increasing time from 30 to 40 min (figure 5d), nanoflowers were synthesized. With enhancement time to $50 \mathrm{~min}$, the rod-like structures start to degrade and eventually generate various nanoparticles (figure $6 \mathrm{~b}$ ).

Different solvents with various surface tensions were used. Figure 7 shows SEM image of $\mathrm{CuInS}_{2}$ nanorods with an average diameter of $90 \mathrm{~nm}$ that is synthesized in water. Rod-like morphology is due to the presence of solvent with lower surface tension. Glycerol has high surface tension, so this power was not able to produce bubbles in solvent, and $\mathrm{CuInS}_{2}$ was not obtained.

Power effect on the morphology of products was examined. At power of $50 \mathrm{~W}$, nanoparticles were aggregated (figure 8a). By increasing power, more energetic bubbles produce nanoparticles with better distribution (figure $8 \mathrm{~b}$ ). At higher power, particles have more kinetic energy that shows preferential growth, resulting in the formation of nano-flowers (figure $5 \mathrm{~d}$ ).

Figure 9 shows TEM image of $\mathrm{CuInS}_{2}$ nanoparticles with an average diameter of $50 \mathrm{~nm}$. Photoluminescence (PL) measurement of $\mathrm{CuInS}_{2}$ nanoparticles (no. 4) was 
carried out at room temperature with excitation wavelength at $418 \mathrm{~nm}$ that is shown in figure 10. The PL spectrum consists of one strong peak at $554 \mathrm{~nm}$ that can be

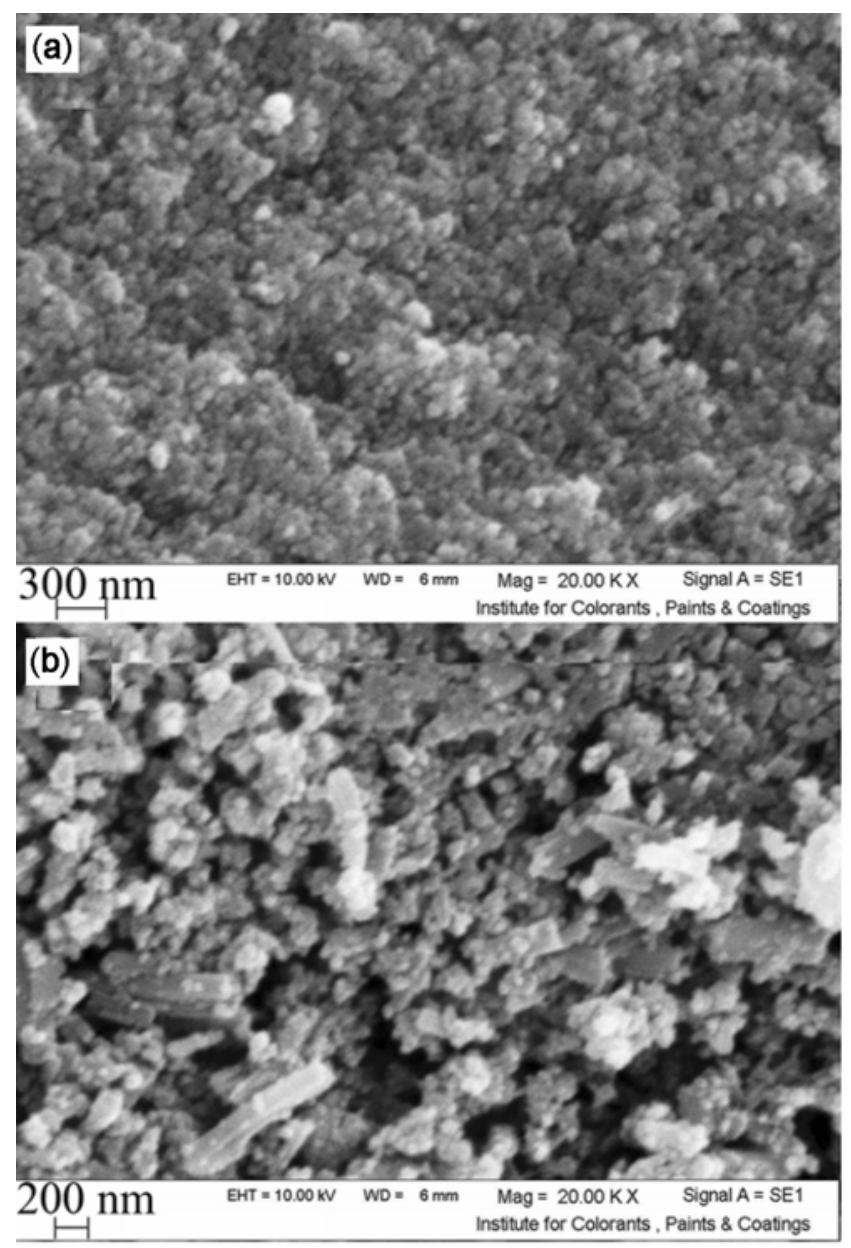

Figure 6. SEM images of the $\mathrm{CuInS}_{2}$ nanostructure with (a) 30 min (sample no. 8), (b) 40 min (sample no. 6) and (c) 50 min (sample no. 9).

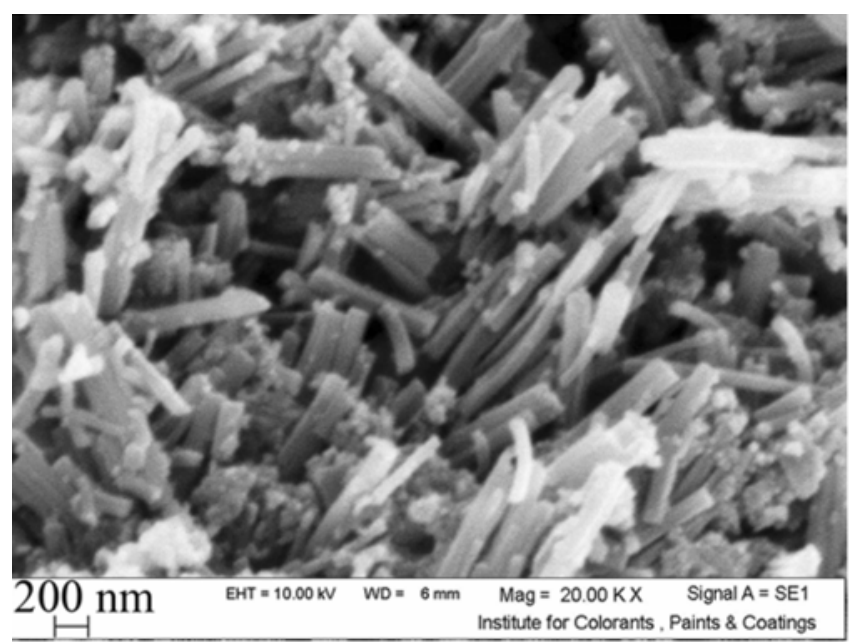

Figure 7. SEM image of the $\mathrm{CuInS}_{2}$ nanostructure in the water as solvent (sample no. 10). ascribed to a high-level transition in $\mathrm{CuInS}_{2}$ semiconductor crystallites. It is reported that this kind of band-edge luminescence arises from recombining shallowly and exactions trapped electron-hole pairs.

The $\mathrm{In}^{3+}$ and $\mathrm{Cu}^{2+}$ ions reacted with the $\mathrm{S}^{-2}$ ions to form the sulphide compounds of $\mathrm{CuS}$ and $\mathrm{In}_{2} \mathrm{~S}_{3}$ according to (1) and (2). The reaction for forming stoichiometric $\mathrm{CuInS}_{2}$ during annealing process might be given in (3).

$$
\begin{aligned}
& \mathrm{Cu}^{2+}+\mathrm{S}^{2-} \rightarrow \mathrm{CuS}, \\
& 2 \mathrm{In}^{+3}+3 \mathrm{~S}^{2-} \rightarrow \mathrm{In}_{2} \mathrm{~S}_{3}, \\
& 2 \mathrm{CuS}+\mathrm{In}_{2} \mathrm{~S}_{3} \rightarrow 2 \mathrm{CuInS}_{2}+\mathrm{S} .
\end{aligned}
$$

$\mathrm{CuInS}_{2}$ thin film was prepared by doctor's blade technique. Figure 11 shows SEM image of $\mathrm{CuInS}_{2}$ thin film surface. The particles are homogeneously distributed in film but many spaces exist between particles in the layer. These voids can trap electron and decrease current short circuit current.

$\mathrm{J}-\mathrm{V}$ curves give key parameters to explain solar cell characterization such as short-circuit current $\left(J_{\mathrm{SC}}\right)$,
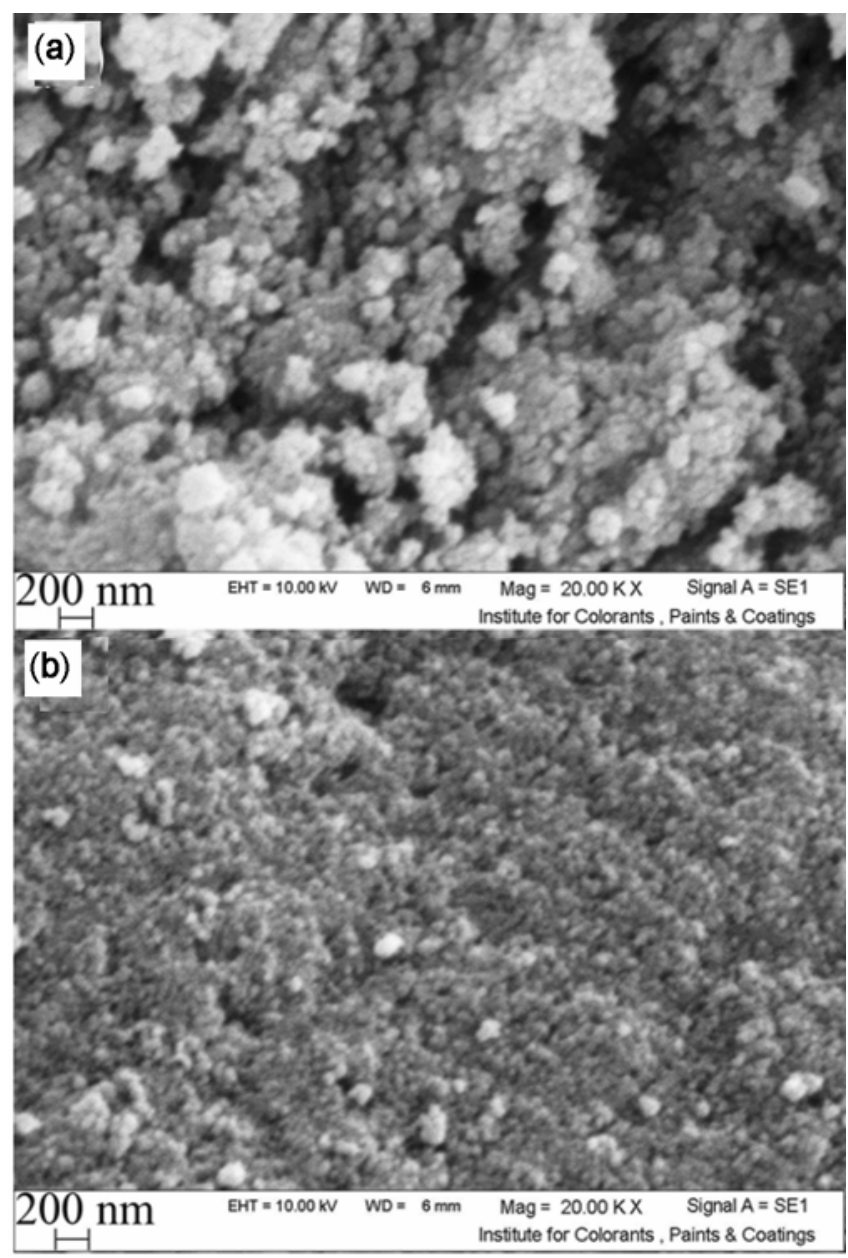

Figure 8. SEM images of the $\mathrm{CuInS}_{2}$ nanostructure at different power (a) $50 \mathrm{~W}$ (sample no. 12) and (b) $60 \mathrm{~W}$ (sample no. 13). 


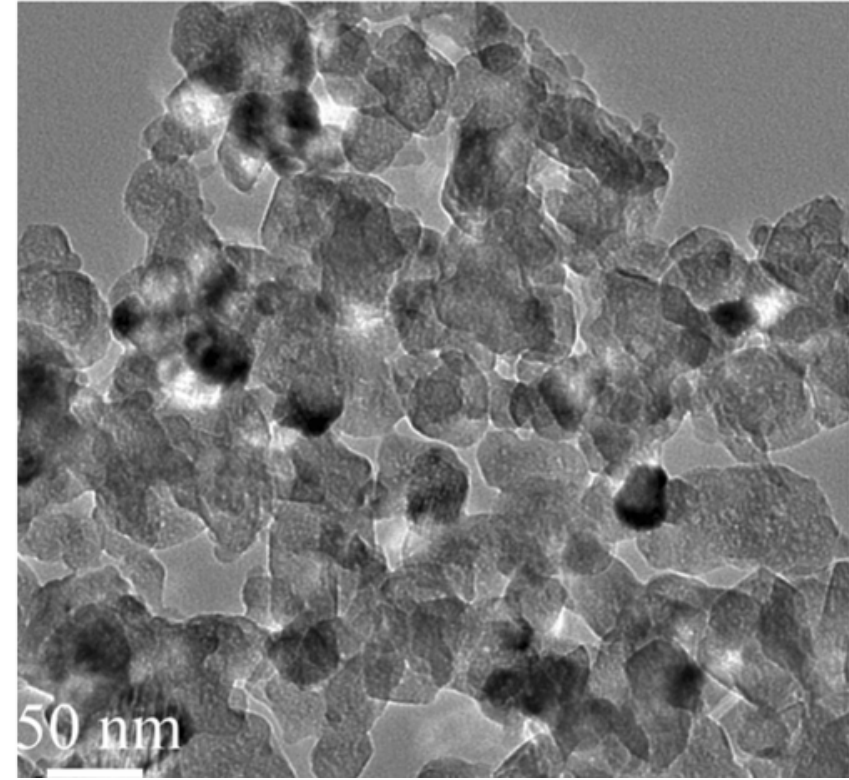

Figure 9. TEM image of the $\mathrm{CuInS}_{2}$ nanostructure (sample no. 4).

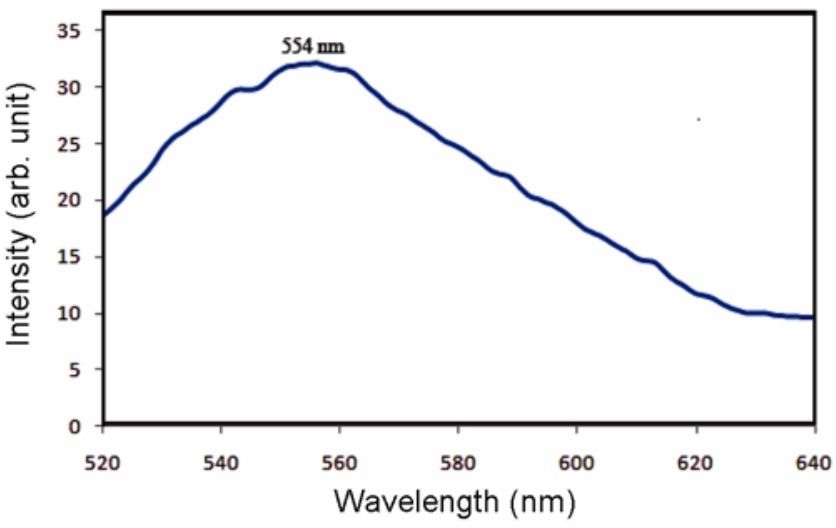

Figure 10. Room temperature photoluminescence spectrum of $\mathrm{CuInS}_{2}$ (sample no. 4).

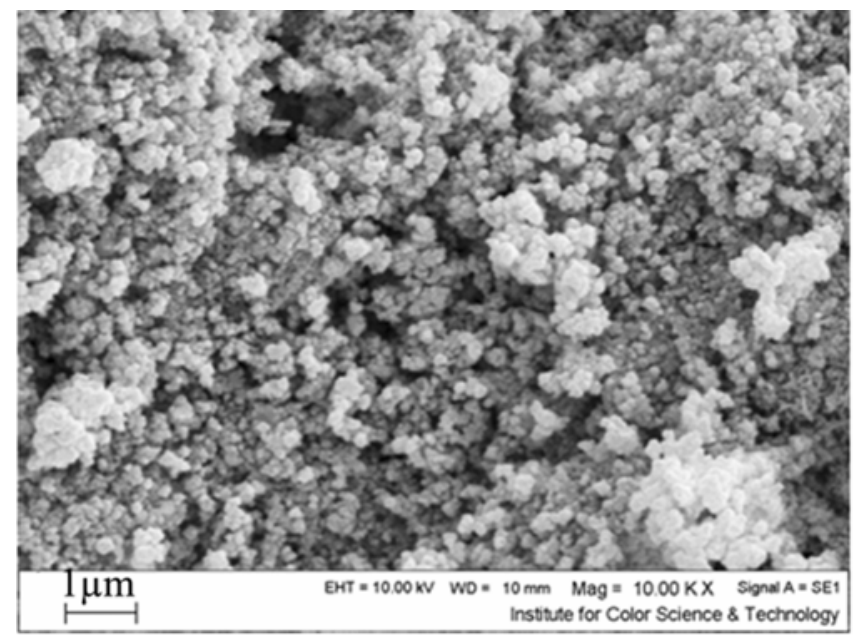

Figure 11. SEM image of thin film $\mathrm{CuInS}_{2}$.

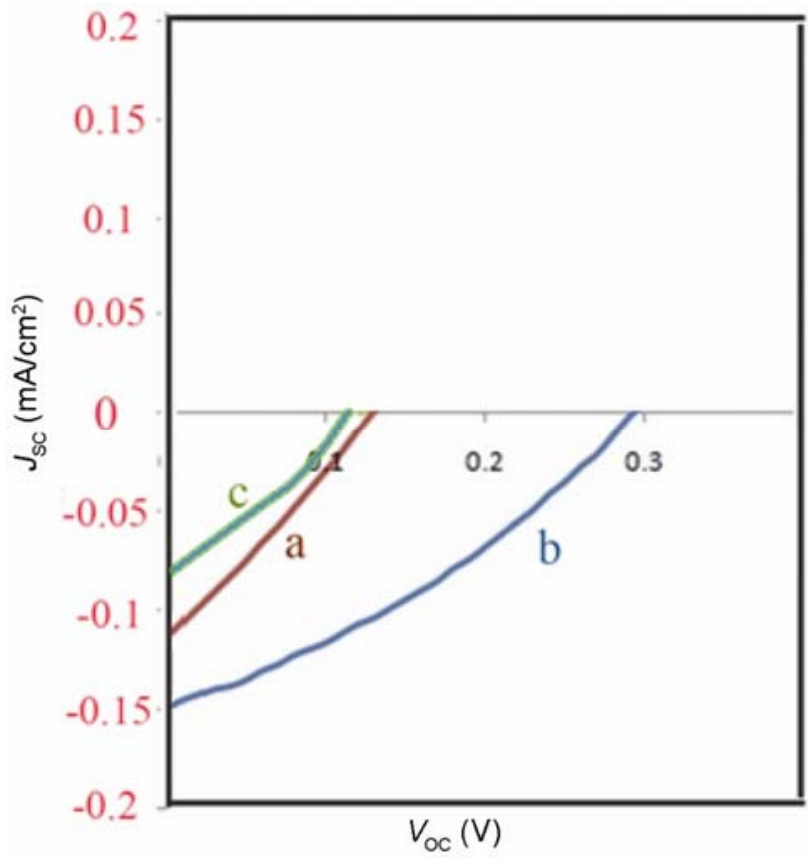

Figure 12. A representative I-V curve of a $\mathrm{CuInS}_{2}$ nanoparticle (a) $100 \mu \mathrm{m}$, (b) $120 \mu \mathrm{m}$ and (c) $220 \mu \mathrm{m}$.

open-circuit voltage $\left(V_{\mathrm{OC}}\right)$ and fill factor. The effect of thin film thickness on these parameters was investigated. When thickness was about $\sim 10 \mu \mathrm{m}, V_{\mathrm{oc}}, J_{\mathrm{SC}}$ and fill factor were obtained as $129 \mathrm{mV}, 0.112 \mathrm{~mA} / \mathrm{cm}^{2}$ and $28 \%$, respectively. A representative $\mathrm{J}-\mathrm{V}$ curve of a $\mathrm{CuInS}_{2}$ nanoparticles device is shown in figure 12(a). By increasing the thickness to $\sim 12 \mu \mathrm{m}, V_{\mathrm{oc}}, J_{\mathrm{SC}}$ and FF were achieved $270 \mathrm{mV}, 1.47 \mathrm{~mA} / \mathrm{cm}^{2}$ and $0.32 \%$, respectively (figure 12(b)). With further enhancement of the thickness to $22 \mu \mathrm{m}, V_{\text {oc }}, J_{\text {sc }}$ and $\mathrm{FF}$ were obtained as $70 \mathrm{mV}$, $0.81 \mathrm{~mA} / \mathrm{cm}^{2}$ and $0.24 \%$, respectively (figure $12 \mathrm{c}$ ).

As shown in the curves, it was found that by increasing the thickness from 10 to $12 \mu \mathrm{m}$, short circuit current, open-circuit voltage and fill factor have been increased. Also with further increase to $22 \mu \mathrm{m}$, these parameters have been decreased in respect to $12 \mu \mathrm{m}$. The main reason for this deterioration is increase in electron recombination by increasing the thickness. So, it is concluded that the optimum thin-film thickness is $12 \mu \mathrm{m}$.

\section{Conclusions}

Copper indium sulphide nanostructures were successfully synthesized from $\mathrm{Cu}(\mathrm{Hsal})_{2}$ precursor by a facile sonochemical method. The effects of different parameters such as sulphur source, solvent, power of irradiation and reaction time on the morphology of the products were investigated. CuInS 2 thin film was deposited on the glass substrates by Dr-blading and it is applied into solar cell and measured $V_{\mathrm{oc}}, J_{\mathrm{sc}}$ and FF. 


\section{Acknowledgement}

Authors are grateful to the Council of Iran National Science Foundation and University of Kashan for supporting this work by grant no. (159271/61).

\section{References}

Castro S L, Bailey S G, Raffaelle R P, Banger K K and Hepp A F 2003 Chem. Mater. 153142

Dutta D P and Sharma G 2006 Mater. Lett. 602395

Du W M, Qian X F, Yin J and Gong Q 2007 Chem. Eur. J. 13 8840

Emst K, Belaidi A and Konenkamp R 2003 Semicond. Sci. Technol. 18475

Esmaeili-Zare M, Salavati-Niasari M and Sobhani A 2012 Ultrason. Sonochem. 191079

Gardner J S, Shurdha E, Wang C M, Lau L D, Rodriguez R G and Pak J J 2008 J. Nanopart. Res. 10633

Jiang Y, Wu Y, Mo X, Yu W C, Xie Y and Qian Y T 2000 Inorg. Chem. 392964

Kaiser I, Emst K and Fischer Ch-H 2001 Sol. Energy Mater. Sol. Cells 6789
Klaer J, Klenk R and Schock H W 2007 Thin Solid Films 515 5929

Long F, Wang W M, Tao H C, Jia T K, Li X M, Zou Z G and Fu Z Y 2010 Mater. Lett. 64195

Moller J, Fischer Ch-H and Siebentritt S 1998 Vienna 610

Nairn J J, Shapiro P J, Twamley B, Pounds T, Von Wandruszka R, Fletcher T R, Williams M, Wang C and Norton M G 2006 Nano Lett. 61218

Nekamp R K, Emst K, Fishcher Ch-H and Lux-Steiner M C 2000 Phys. Status Solidi 18215

Salavati-Niasari M, Hosseinzadeh G and Davar F 2011 J. Alloy Compd. $\mathbf{5 0 9} 134$

Shay J L and Wernick J H 1975 Ternary chalcopyrite semiconductors: growth, electronic properties and applications (International series of monographs in the science of the solid state, vol. 7) (New York: Pergamon Press) p. 7

Xiao J P, Xie Y, Tang R and Qian Y T 2001 J. Solid. State Chem. 161179

Yamamoto Y, Yamaguchi T, Tanaka T, Tanahashi $\mathrm{N}$ and Yoshida A 1997 Sol. Energy Mater. Sol. Cells 49399

Zhang A Y, Ma Q, Lu M K, Yu G W, Zhou Y Y and Qiu Z F 2008 Cryst. Growth Des. 82402

Zhu G, Su F F, Lv T, Pan L K and Sun Z 2010 Nanoscale Res. Lett. 51749 